\title{
Philosophiques
}

\section{Michel Cornu, Patience du Détachement, Lausanne, l'Âge d'Homme (col. Essais), 1989, 121 p.}

\section{G. Boss}

Volume 17, numéro 1, printemps 1990

URI : https://id.erudit.org/iderudit/027116ar

DOI : https://doi.org/10.7202/027116ar

Aller au sommaire du numéro

Éditeur(s)

Société de philosophie du Québec

ISSN

0316-2923 (imprimé)

1492-1391 (numérique)

Découvrir la revue

Citer ce compte rendu

Boss, G. (1990). Compte rendu de [Michel Cornu, Patience du Détachement, Lausanne, l'Âge d'Homme (col. Essais), 1989, 121 p.] Philosophiques, 17(1), 164-164. https://doi.org/10.7202/027116ar d'utilisation que vous pouvez consulter en ligne.

https://apropos.erudit.org/fr/usagers/politique-dutilisation/ 
MiChel Cornu, Patience du Détachement, Lausanne, l'Âge d'Homme (col. Essais), 1989, $121 \mathrm{p}$.

\author{
par G. Boss
}

Dans cet essai, écrit sous forme d'aphorismes et de petits chapitres de caractère suggestif plus que vraiment démonstratif, l'auteur poursuit la réflexion morale qu'il avait commencée dans des ouvrages plus académiques par leur style: Kierkegaard et la Communication de l'Existence et Existence et Séparation. Il s'agit d'une critique de la morale moralisante fondée sur la recherche de la maîtrise, et de la proposition d'une autre attitude, d'ouverture au monde, au temps et à l'autre.

Le point de départ de la réflexion est la reconnaissance de la réalité inacceptable de la souffrance et du mal, ainsi que du défaut originaire du sujet, incapable de comprendre sa naissance et exposé à la mort. La tentative de maîtrise du monde, des autres, du destin et de soi-même représente la stratégie habituelle pour constituer une totalité fermée grâce à laquelle le sujet croit pouvoir évacuer son défaut originaire. Cette illusion de l'autonomie est dénoncée dans une série d'approches de divers thèmes moraux, qui la dénichent dans ses figures les plus insidieuses, comme par exemple la recherche de la justification par la bonne conscience ou la culpabilisation, la crispation sur le plaisir dans l'ascèse et la débauche, l'appropriation de l'autre dans le confort bourgeois du mariage comme dans la maîtrise de la séduction par la technique du séducteur, voire l'attachement à la supposée vraie théorie morale. L'effort pour éviter ces modes d'enfermement exige une attitude inverse, de reconnaissance du caractère injustifié de notre existence, d'acceptation du plaisir comme don du destin, sans résignation à une quelconque fatalité, d'ouverture à une relation jouée, de connivence, avec autrui, d'abandon à la séduction. La figure de l'exode, parmi d'autres, définit cette recherche du détachement en une marche qui n'est ni le déménagement le long de routes déjà reconnues, ni l'errance simple, mais un cheminement en direction d'une lumière devinée plus que réellement perçue. D'ailleurs, à l'espoir, qui se fonde toujours ultimement sur des probabilités tirées de l'expérience passée, la pensée du détachement oppose l'espérance, gratuite, généreuse, qui ne se contente pas du bien futur, mais espère la réversibilité du temps et la possibilité du grand pardon.

Le détachement, remarque l'auteur, est à certains égards une entreprise de riches ( «ce qui, au premier regard paraît noblesse du désintéressement, pourraic bien représenter une arrogance à l'égard de ceux pour qui, si démunis sont-ils, le détachement est impossible.»p. 12). Cette richesse est également celle d'une culture morale, qui permet à $\mathbf{M}$. Cornu le jeu de distinctions subtiles et intéressantes entre des concepts voisins, grâce auxquelles il nuance délicatement ses positions, proposant au lecteur une quotidienneté moralement très intellectualisée. 